\title{
AUTORES ESPAÑOLES EN LA BIBLIOTECA IDEAL DE GABRIEL NAUDÉ (1627): UNA VISIÓN EUROPEA DE LA CULTURA Y LA CIENCIA ESPAÑOLAS A COMIENZOS DEL XVII
}

\author{
Evaristo Álvarez Muñoz
}

Universidad de Oviedo

\section{RESUMEN}

Se analizan las sugerencias bibliográficas de autores españoles mencionados en Advis pour dresser une bibliotheque (1627) de Gabriel Naudé, excelente observatorio de la cultura europea que ofrece un interesante reflejo de la ciencia y la cultura españolas a comienzos del siglo XVII. Este artículo repasa una visión extranjera de la cultura española en un momento histórico crucial.

PALABRAS CLAVE: Gabriel Naudé. Ciencia española moderna. Cultura española y europea de los siglos XVI y XVII. Bibliotecas del siglo XVII.

\section{SPANISH AUTHORS IN THE IDEAL LIBRARY OF G. NAUDÉ (1627): A EUROPEAN VIEW OF THE SPANISH CULTURE AND SCIENCE AT THE BEGINNING OF THE 17TH CENTURY}

\begin{abstract}
This article aims to analyze a European view of the 17th century Spanish culture. Naude's Advis pour dresser une bibliothèque (1627) — translated twice into English: Instructions concerning erecting of a library (1661) and Advice on establishing a library (1950) - represents a wide set of bibliographic recommendations that constitute, among many other things, an excellent observatory of the Spanish culture in such a delicate time.

KEY WORDS: Gabriel Naudé. Spanish modern Science. Spanish and European Cultures in the 16 th and 17 th centuries. 17 th century Libraries.
\end{abstract}




\section{LAS RECOMENDACIONES PARA FORMAR UNA BIBLIOTECA}

Advis pour dresser une bibliothèque — en lo sucesivo Recomendaciones para formar una biblioteca ${ }^{1}$ o, simplemente, Recomendaciones-, obra escrita en 1627 por el erudito parisino Gabriel Naudé (1600-1653), pasa por ser el primer tratado de bibliotecas en el que se abordan todos los asuntos biblioteconómicos, desde los relativos al orden y mantenimiento de los libros hasta los referidos a la selección y adquisición de los mismos. Tal vez los primeros aspectos hayan sido los más celebrados por los especialistas en bibliotecas, mientras que los segundos fueron bastante descuidados por filósofos y estudiosos. Sin embargo, las Recomendaciones apuntan hacia una auténtica biblioteca selecta o biblioteca ideal que proporciona datos preciosos tanto acerca de la época como de la percepción que de la misma tenían sus intérpretes coetáneos. Su autor, Gabriel Naudé ${ }^{2}$, fue un bibliotecario y polígrafo parisino, autor de más de una treintena de obras sobre los numerosos temas en que estaba interesado: política, medicina, ciencia y falsa ciencia, bibliografía o historia.

La solvencia intelectual de Naudé y sus amplios conocimientos bibliográficos hacen de él un riguroso notario de esa gran transformación del mundo acontecida en las primeras décadas del siglo XVII, en las que algunos ven un otoño del Renacimiento europeo ${ }^{3}$ y que para la ciencia hispánica supuso la entrada en un largo invierno. El asentamiento de los ideales humanistas y la ruptura provocada por la Reforma - y por la Contrarreforma - religiosa generaron una inexorable sucesión de cambios al tiempo que los estados modernos definían sus límites geográficos y psicológicos, en plena efervescencia de las polémicas vernáculas entre antiguos y modernos.

Efectivamente, no fue la de Naudé una época cualquiera para la historia de las ideas. En 1617 había fallecido Francisco Suárez, el último gran escolástico,

1 NAUdÉ, G. (1627), Advis pour dresser une bibliothèque [Reprod. fac-sim. de la ed. de: Paris, Rolet Le Duc, 1644], Paris, Aux Amateurs de Livres, 1990. XXIV, 164 p. Existe una reciente traducción española: NAUDÉ, G. (2008), Recomendaciones para formar una biblioteca (edición de Álvarez MuÑoz, E.), Oviedo, KRK, 387 p. A esta edición, primera en castellano, se refieren los datos y citas del presente artículo.

2 Sobre Naudé pueden consultarse las biografías de RICE, J.V. (1939), Gabriel Naudé, 1600-1653, Baltimore, John Hopkins Press; o la que con el mismo título le dedicó ClARKE, J.A. (1970), Hamden, Conn., Archon Books; así como el retrato literario de SAINTE-BEUVE, Ch.-A. (1862), Gabriel Naudé. En Portraits littéraires, Paris, Garnier Frères, vol. II, pp. 467-512.

3 Bouwsma, W. J. (2000), The Waning of the Renaissance 1550-1640, New Haven, Yale University Press, 2001. 288 p. Existe versión castellana BouWSMA, W. J. (2001), El otoño del Renacimiento, 1550-1640 (trad. de Silvia Furió), Barcelona, Crítica, 2001, 368 p. 
$\mathrm{y}$, con la decadencia escolástica, se precipitó la del aristotelismo, que llevaba siglos campeando. En vano los poderosos jesuitas recogerían el testigo de los dominicos en sus disputas teológicas. Cada vez parecía más remoto el día en que un precozmente desencantado Hugolino Malebranche había afirmado philosophia propie loquendo non est scientia sed mixtura falsorum. Francis Bacon acababa de publicar el Novum Organum scientiarum (1620) — que habría de sustituir al viejo Organon aristotélico- y De dignitate et augmentis scientiarum (1623). El mismo año en que apareció Recomendaciones, Kepler finalizaba las Tablas Rudolfinas y Galileo estaba gestando Dialogo sopra $i$ due massimi sistemi del mondo, tolemaico e copernicano (publicado en 1632), que le valdría la condena papal por caricaturizar el aristotelismo en la figura de Simplicio. Claro que la perfección del mundo supralunar ya había quedado hecha trizas en Sidereus Nuncius (1610) al denunciar Galileo las irregularidades de la Luna; y los satélites merodeando Júpiter habían hecho lo propio con el estable esquema ptolemaico. El golpe decisivo al pensamiento antiguo habría de darlo un contemporáneo de Naudé, René Descartes (15961650), quien en el momento de publicarse Recomendaciones aún no se había estrenado como publicista. En aquella época crítica se dieron firmes pasos en lo que hoy recordamos como Revolución científica.

Tan someramente situados en la coyuntura científico-filosófica de 1627, ¿por qué la obra de Naudé habría de tener especial interés para la historia de las ideas y, más concretamente, en la de los autores españoles? La razón reside en un presupuesto de partida de Recomendaciones que no es otro que el de la universalidad. La biblioteca de Naudé pretende ser una biblioteca universal, pero no en el sentido exhaustivo de Conrad Gesner ${ }^{4}$, sino en el mucho más pragmático de la selección recomendada. Una selección que plantea mayores exigencias críticas al compilador, al bibliotecario ideal que, como afirma nuestro autor, «no nace todos los años». No exagera Naudé. Ni siquiera él podría garantizar que el elenco de autores escogidos fuera el mejor posible, si bien sería difícil hallar en su época a otro crítico independiente más predispuesto a asumir

el esfuerzo y la dificultad que representa adquirir un conocimiento superficial de todas las artes y las ciencias, desembarazarnos de la servidumbre y la esclavitud de ciertas opiniones que nos llevan a decidir y a hablar caprichosamente de cualquier cosa y juzgar rectamente y sin pasión acerca del mérito y la calidad de los autores ${ }^{5}$.

4 GeSner, C. (1545), Bibliotheca universalis, Tiguri, Christophorum Froschoverum.

5 NAUDÉ (2008), p. 80. 
Tampoco hace Naudé una elección literaria ${ }^{6}$-no encontraremos en Recomendaciones a los narradores y dramaturgos franceses, ni a los españoles del Siglo de Oro- sino que en su ánimo estaba disponer en su biblioteca de

los libros fundamentales de las principales facultades y otros muchos que pueden servir en distintas investigaciones sobre temas particulares y menos comunes.

Libros que serán instrumentos de estudio — vt illi sint caenationum ornamenta, quam vt studiorum instrumenta - mediante los cuales

todo puede saber, verlo todo y no ignorar nada. ${ }^{7}$

Así pues, con la excepción de los clásicos latinos y griegos y de algunos humanistas italianos que merecerían compartir pedestal con los antiguos -Dante, Boccaccio, Petrarca, Ariosto, Tasso-, los autores y libros citados por Naudé serían hoy día calificados de «no ficción» en los listados de libros recomendados, pues

los estudios morales y políticos ocupan la mayor parte de los mejores y más fuertes espíritus de nuestro tiempo, mientras que los más débiles se entretienen con las ficciones y novelas, de las cuales sólo repetiré lo que de tales narraciones dijo Símaco: Sine argumento rerum loquacitas morosa desplice. ${ }^{8}$

No se busque por tanto a Rabelais ni a Shakespeare ni a Cervantes entre las lecturas recomendadas, sólo se encontrarán libros para la instrucción y el conocimiento publicados entre el Renacimiento y la Revolución científica y tratados científicos antiguos recuperados para la edad moderna. Sólo obras que, en su conjunto, forman un árbol de la ciencia del que brotan la teología positiva, la filosofía escolástica, el derecho civil y canónico, la medicina, la astrología, la óptica, la aritmética, el estudio de los sueños, etc. —ramas que Naudé intentará sanear o podar esbozando una sistematización heredera de las facultades medievales y de la evolución de las artes liberales característica del humanismo y que ya anuncia las clasificaciones científicas modernas.

No nos resistimos a señalar que Gabriel Naudé y Baltasar Gracián (16011658) fueron casi estrictamente contemporáneos, aunque el español no comenzaría a publicar hasta dos décadas después de la aparición de Recomen-

6 DAMIEN, R. (2002), Gabriel Naudé et la lecture des romans. Libertinage et philosophie au XVIIe siècle, 6, 73-82.

7 NAUDÉ (2008), pp. 82 y 90-91.

8 NAUDÉ (2008), p. 139. 
daciones, que es obra de juventud, impresa cuando su autor contaba apenas veintisiete años. En cierto modo, sólo la osadía de la juventud puede justificar una selección tan comprometida. De hecho, la segunda mitad de su vida la dedicaría Naudé a recopilar, para otros patronos — los cardenales Bagni y Mazarino o la reina Cristina de Suecia-, los libros de la formidable biblioteca que había planteado a De Mesme.

Otra curiosidad relacionada con España: hacia 1556, Juan Páez de Castro (a quien no cita Naudé) había dirigido una Memoria a Felipe II sobre la utilidad de juntar una buena biblioteca ${ }^{9}$ —inédita hasta 2003, pero que sin duda fue consultada por Cardona para redactar De regia S. Laurentii bibliotheca (1587) - cuyos sorprendentes parecidos en el planteamiento y la multitud de referencias idénticas a las Recomendaciones de Naudé se resisten a ser considerados meras coincidencias. Es posible que Páez de Castro influyera secretamente en Naudé a través de Cardona.

La obra de Naudé supone - con la mera inclusión o exclusión de una cita - una crítica radical realizada en un momento de inflexión en la historia de las ideas especialmente significativa para la historia del pensamiento español, que ve cómo todo su esplendor artístico-literario y potencial político se sume, en la primera mitad del XVII, en una penuria intelectual y científica difícil de explicar o, peor aún, explicada en ocasiones con esquemas excesivamente simplistas ${ }^{10}$.

En tal sentido, Recomendaciones es un magnífico indicador del final de una época marcada por el escolasticismo aristotélico y la autoridad de lo escrito y el comienzo de otra en la que una nueva filosofía experimental de la naturaleza cuestiona la autoridad de los dogmas. Este proceso intelectual o científico sigue inmediatamente al ideológico y político que supusieron la Reforma y la subsiguiente Contrarreforma religiosas y del que es tópico, asumible en líneas generales, señalar el hecho de que los países católicos, España especialmente, salieron peor parados con vistas a los nuevos tiempos que se acercaban.

9 PÁEz de CAStro, J. (2003), Memoria a Felipe II sobre la utilidad de juntar una buena biblioteca, [s.1.], Junta de Castilla y León, 117 p.

10 Nos referimos a la conocida polémica sobre la ciencia española entre panegiristas y pesimistas críticos. La citada controversia, sobre la que se escribieron cientos de páginas, fue rigurosamente analizada, entre otras obras, en LÓPEZ PIÑERO, J. M. (1979), Ciencia y técnica en la sociedad española de los siglos XVI y XVII, Barcelona, Labor; en PARDO TOMÁs, José (1991), Ciencia y censura: la Inquisición española y los libros científicos en los siglos XVI y XVII, Madrid, CSIC; y en NAVARro Brotóns, V. Y EAmon, W., eds. (2007), Más allá de la Leyenda Negra: España y la Revolución Científica, Valencia, Instituto de Historia de la Ciencia y Documentación López Piñero, 529 p. 


\section{LA IDEOLOGÍA Y EL RIGOR DEL BIBLIOTECARIO NAUDÉ}

Naudé, un erudit libertin - entiéndase en el sentido de librepensador-, selecciona los libros con criterios amplios, convencido de que la discusión entre puntos de vista diferentes es necesaria para aclarar la verdad, por lo que, en la biblioteca, junto con los libros sagrados, aconseja

no desatender ninguna obra de los principales heresiarcas o fundadores de nuevas religiones diferentes de la nuestra (...) que, exceptuando ciertos pasajes controvertidos, se pueden encontrar buenas cosas en el resto ${ }^{11}$ y hasta lo justifica cabalmente puesto que es necesario que nuestros doctores los encuentren en alguna parte para poder refutarlos (...) no debiera causar ningún escrúpulo el hecho de poseer un Talmud o un Corán que vomitan mil blasfemias contra Jesucristo y nuestra religión, mucho más peligrosos que las obras de los heréticos, pues Dios nos permite sacar provecho de nuestros enemigos siguiendo lo que dice el salmista: Salutem ex inimicis nostris, \& de manu omnium qui oderunt nos.

Este ánimo contrastivo y polemista no es mero posicionamiento ideológico, sino que pasa a ser una exigencia técnica de la biblioteca. La organización bibliotecaria participa en la dialéctica y se nutre de ella y así, en cada rúbrica - desde la teología hasta la botánica-, ha de incluir a los autores clásicos, por supuesto, pero también a sus comentadores, polemistas y detractores, así como a los innovadores modernos.

Naudé advierte simultáneamente el dogma y el cambio en todos los aspectos de aquella sociedad en transformación. Bibliófilo y erudito, es capaz de percibir que el dogma no sólo gravita alrededor de las escrituras sagradas sino que puede estar en la aceptación acrítica de los clásicos y en el gusto reverencial por las cuidadas ediciones de lujosa encuadernación. El dogma - que puede estar en los libros sagrados, o en Aristóteles, o en los detractores de éste, o en los heréticos- debe convivir, en una biblioteca que se precie, con sus comentaristas y refutadores.

En la biblioteca ideal de Naudé deberá incluirse a

todos aquellos que mejor comentaron o explicaron determinado autor o libro en particular (...) Esto se deberá observar con todo tipo de libros y tratados antiguos o modernos que hayan sido objeto de interpretaciones y comentarios.

11 Todas las citas de este apartado II han sido extraídas de NAUDÉ (2008), pp. 116-126 (en concreto y correlativamente de las páginas: $126-7,127-8,116-7,119$ y 121-2, 122-3 y 126) 
A continuación todos aquellos autores que han escrito ventajosamente contra alguna ciencia, o incluso los que se han opuesto con más doctrina y animosidad (...) y, para finalizar, a todos aquellos que ejercieron semejante esgrima y que están de tal manera encadenados los unos a los otros que sería tan grave error leerlos separadamente como juzgar y entender una parte sin la otra o un contrario sin su opuesto.

Tampoco se debe omitir a ninguno de los innovadores o de los que han modificado algún aspecto de las ciencias (...) Por eso —en vista de que desde hace poco más de treinta o cuarenta años autores prestigiosos se declararon contra Aristóteles; de que Copérnico, Kepler y Galileo han dado un vuelco a la astronomía; de que Paracelso, Severino el danés, Du Chesne y Crollius hicieron lo propio con la medicina y de que muchos otros han introducido nuevos principios y construido sobre ellos razonamientos extraños, inauditos y antes nunca vistos- yo sostengo que todos estos autores son muy necesarios en una biblioteca, pues como se suele decir: Est quoque cunctarum nouitas gratissima rerum.

Difícilmente se podría definir más claramente la intencionalidad de la biblioteca naudeana y el rigor con el que su autor pretende construirla. De hecho, el lector actual tal vez se haga más fácilmente cargo de la receptiva disposición de Naudé a partir de la extrañeza que hoy le produce la coexistencia en las estanterías de astrólogos, alquimistas y magos junto con Galileo y Copérnico.

A pesar de que la mayoría de estos no enseñan más que cosas vanas e inútiles y de que yo los considero unos escollos para quienes se entretienen con ellos, también es cierto que - para contentar a los espíritus débiles, no sólo a los fuertes, y para satisfacer al menos a los que quieren verlos para refutarlos- es necesario recopilar estos tratados entre los otros libros de la biblioteca - de igual manera que hay serpientes y víboras junto a los demás animales y cizaña entre el buen trigo y espinas en las rosas - a ejemplo del mundo, en el que cosas inútiles y peligrosas suceden en el interior de la obra maestra.

¿Podría tratarse de vulgar eclecticismo remiso a tomar partido?, ¿podría denunciar ciertas carencias científicas o desconocimiento de los contenidos por parte de Naudé? En nuestra opinión, el compromiso y la osadía del bibliotecario - de quien se dice que llegó a utilizar el Index librorum prohibitorum como la más interesante bibliografía - están a salvo de toda duda. Naudé es un sujeto de su tiempo y su selección no es un trabajo inane ni neutral sino orientado por un especial sentido de la historia que inclina sus ideas de forma inconfesa, pero inconfundible, del lado de los modernos sin renunciar en ningún caso a la sabiduría de los antiguos. 


\section{LOS AUTORES CITADOS POR NAUDÉ Y SUS ORÍGENES NACIONALES}

En Recomendaciones se citan, según nuestros cómputos, 360 personajes, de los que 17 son legendarios (Trimegisto, Carpentra, Evandro), bíblicos (Ezequiel, Salomón) o históricos (Alejandro Magno, Francisco I, Jerjes, etc.), que descontados del total dejan el número nada despreciable de 343 autores. En realidad no todos esos 343 - aunque sí la mayoría - tienen obra escrita que los haga acreedores del título de autores. Algunos son citados en su condición de editores, traductores, bibliotecarios, bibliófilos o mecenas. De algún otro de los mencionados se han perdido las obras. Si ordenamos los 360 personajes citados cronológicamente (atendiendo a sus fechas de fallecimiento), encontramos que 82 habrían fallecido antes de 476 d.C. y, por tanto, los consideraremos «antiguos»; 13 pertenecerían a la «alta edad media» (hasta el año 1000); otros 44 a la «baja edad media» (fallecidos entre 1000 y 1453) y 221 autores fallecidos después de 1453 , que podríamos considerar modernos. Se podría inferir que, sin desatender a los clásicos, Naudé mostraba más interés por los autores modernos.

Por nacionalidades - aunque este concepto no tiene mucho sentido antes de la época moderna o, como mucho, de la baja edad media - los más numerosos son los italianos, con 90 autores citados; siguen los franceses ${ }^{12}$ con 76; los alemanes con 27 y los españoles con 26 autores. También son citados 14 flamencos, holandeses o belgas, 9 ingleses y 6 suizos. En la obra de Naudé hay también autores portugueses, polacos, escoceses, húngaros, griegos y croatas. No se han adjudicado a ningún país los autores anteriores al año 1000.

La identificación de los autores ${ }^{13}$ no fue inmediata en todos los casos. Así, entre los españoles citados persisten algunas dudas en el caso de «Nunnesius», del que sólo nos cuenta que poseyó una biblioteca de difícil acceso y que creemos puede tratarse de Pedro Juan Núñez (1529-1602), y de «Sánchez», apellido bajo el que hemos identificado al médico Francisco Sánchez (c.a.1550-1623), aunque no se debería descartar totalmente a Francisco Sánchez de las Brozas (1523-1601). En cuanto a la españolidad o no de algunos de ellos tampoco está claro si Francisco Sánchez y Vasco de Taranta fueron gallegos o portugueses, aunque desde la perspectiva de comienzos del XVII -Portugal formó parte de la corona española entre 1580 y 1640 - la cuestión sea poco relevante.

12 No tenía Naudé propósitos nacionalistas como su compatriota LA CROIX DU MAINE en Bibliothèque française (1584).

13 Más datos y precisiones en NAUDÉ (2008), Apéndice I, pp. 215-353. 


\section{LA SITUACIÓN ESPAÑOLA EN LA ÉPOCA DE RECOMENDACIONES}

En 1627 los efectos de la Contrarreforma se habían dejado sentir en España, aunque los abusos de la Inquisición no habían alcanzado su punto culminante ${ }^{14}$. La ciencia europea todavía se difundía desde las universidades italianas, especialmente desde la más independiente de Padua, que ejercía como poderoso foco de atracción a donde acudió el propio Naudé. Pero desde noviembre de 1559, un decreto de Felipe II ponía trabas a los estudiantes españoles para salir al extranjero.

Añádase a esto las consecuencias de las reales pragmáticas de septiembre de 1558, que prácticamente prohibían la importación y la distribución de libros extranjeros en España ${ }^{15}$, y se comprenderá que - aunque las medidas aislacionistas no arruinaron la vitalidad intelectual del siglo de oro literario y artístico - la ciencia española, la gran perjudicada por el aislamiento, quedara en gran medida marginada de la Revolución científica que acontecía por esas fechas en otros países de Europa. Con todo, desde el interior, Salamanca y Alcalá ejercieron una importante labor docente que significó un gran impulso a los estudios legislativos y económicos, mientras que la historia natural florecía en Hispanoamérica. Fuera de las fronteras, la presencia cultural de España en Europa seguía siendo notable, entre otras causas porque muchos españoles publicaban desde el extranjero.

Si analizamos la producción editorial y la circulación de las publicaciones en España en relación con la censura inquisitorial hay que comenzar recordando que en 1627 estaba vigente el índice de Sandoval de 1612, pero se avecinaba el mucho más intransigente Novus Index de Zapata de 1632, por lo que los edictos de censura que funcionaban corrientemente entre la aparición de cada índice se habían recrudecido. El examen y revisión de obras fue intenso en el período $1612-1640^{16}$, lo que explicaría que muchos españoles publicaran en el extranjero y en latín. Por otro lado, entre los autores españoles citados por Naudé hay al menos dos que ya figuraban a la sazón en los índices inqui-

14 Se puede comprobar un progresivo endurecimiento de los índices inquisitoriales en España, desde Valdés Salas (1559) y Quiroga (1583) hasta Bernardo de Sandoval (1612) y el Novus Index de Zapata (1632), en PARDo Tomás, J. (1991), Ciencia y censura, pp. 50-81 y en J.Reusch, F. H. (1967), Der Index der Verbotenen Bücher: ein Beitrag zur Kirchen- und Literaturgeschichte. Aalen, Scientia, 2 vol.

15 Con algunas excepciones como Plantino, nombrado «architipógrafo» de Felipe II, que estableció una Oficina en Salamanca.

16 PARDO TOMÁs (1991), p. 127. 
sitoriales españoles; se trata de Huarte (índices de 1584 y de 1612, y seguirá después en todos los índices hasta 1966) y de Sabunde (índices de 1584 y de 1612, y después, al menos, en los de 1632 y 1707).

La mayoría de los autores citados eran clérigos, pero se debe observar que entre las diversas órdenes religiosas las relaciones no eran óptimas. El imparable poder e influencia de los jesuitas no era siempre visto con buenos ojos, ni siquiera en la propia España. Como anécdota señalemos que el Índice de 1632 habría de provocar un escrito respaldado por religiosos franciscanos, dominicos y carmelitas a los inquisidores de Toledo en el que se lo criticaba, se defendía la edición de Andrés Laguna de la Materia médica de Dioscórides, muy censurada en aquel Índice, y se acusaba de partidismo a los calificadores inquisitoriales por no censurar debidamente la obra de los jesuitas Salmerón, Henríquez y Tomás Sánchez ${ }^{17}$.

El elenco relativamente abultado de autores españoles citados por Naudé en Recomendaciones no debería sorprender, aunque llaman la atención algunos, bastante olvidados en la actualidad ${ }^{18}$. En 1627 aún no se había generalizado la decadencia cultural ibérica ${ }^{19}$, se mantenía un cierto prestigio y conti-

17 PARDO TOMÁs (1991), pp. 75 y 78.

18 Los datos biográficos y bibliográficos de los autores españoles citados por Naudé han sido extraídos o cotejados con las siguientes obras: ANTONIO, N. (1783), Bibliotheca hispana nova, Madrid, Ibarra, 2 vol. (830, 669 p.) BAYLE, P. (1697), Dictionnaire historique et critique. Reprod. de la ed. de Rotterdam, R. Leers, 2 vol. (1359, 1331 p.) Enciclopedia universal ilustrada europeo-americana, Madrid, Espasa-Calpe, 1958-, 112 vol. EsCOLAR, H. (1994), Historia ilustrada del libro español, vol. 2: De los incunables al siglo XVIII, Madrid, Fundación Germán Sánchez Ruipérez, 586 p. LóPEz PIÑERO, J. M. et al. (1983), Diccionario histórico de la ciencia moderna en España, Barcelona, Península, 2 vol. (554, 573 p.) MenÉndez Pelayo, M. (1933), La ciencia española (ed. Miguel Artigas), Madrid, Librería General de Victoriano Suárez, 2 vol. (476, 494 p.). MENÉndez PElayo, M. (1965), Historia de los heterodoxos españoles. $2^{\mathrm{a}}$ ed., Madrid, Editorial Católica, 2 vol. $(968,1064$ p.) MENÉNDEZ PIDAL, R. (1999), La cultura del Renacimiento, (1480-1580), Madrid, Espasa-Calpe, 882 p. NAVARRO BRotóns, V. et al. (1999), Bibliografia physico-mathematica hispánica (1475-1900), vol. I: 1475-1600, Valencia, Instituto de Historia de la Ciencia y Documentación López Piñero. Palau DuceT, A. (1948-1987), Manual del librero hispano-americano: bibliografia general española e hispanoamericana desde la invención de la imprenta hasta nuestros tiempos, Barcelona, Librería Palau (etc.), 35 vol. PicAtoste, F. (1891), Apuntes para una biblioteca científica española del siglo XVI, Madrid, Imprenta y Fundición de Manuel Tello, 416 p. SIMÓN DíAZ, J. (1951- ), Bibliografia de la literatura hispánica, Madrid, CSIC, XVI vol. YNDURAIN, D. (1994), Humanismo y Renacimiento en España, Madrid, Cátedra, 528 p.

19 López PiÑero, J. M. (1979), p. 377, muestra que en el primer tercio del XVII se prolongó la actividad científica española del siglo anterior y se mantuvo la influencia y el prestigio en Europa. La gran decadencia se produciría con posterioridad a la publicación de Naudé. 
nuaba el flujo de ideas desde la península ibérica hacia el resto de Europa, aunque la información fluía casi en un solo sentido. A comienzos del XVII España era un país embarcado en la empresa contrarreformista y muchos de sus pensadores y publicistas, muchos de ellos eclesiásticos, se habían puesto al servicio de la misma. Es natural que Naudé tienda a asociar en exceso a algunos de los autores españoles que cita con la teología, con la escolástica y con el aristotelismo.

Cierto que en muchas ocasiones la inclusión o exclusión de los autores citados en la relación de Naudé depende de razones aparentemente espurias, como pueden ser la publicación en Francia o la traducción al francés de sus obras. Las prensas de París, Lyon, Lisboa, Roma, Basilea, Venecia o Amberes publicaron durante los siglos XVI y XVII una buena parte de la producción intelectual española en latín. Por su parte, Naudé seleccionaba los libros para una determinada biblioteca, la de Henri de Mesme, presidente del Parlamento de París. Casi todos los libros escogidos podían encontrarse en las librerías parisinas del momento. Esto podría explicar algunas ausencias. La mayoría de los autores citados vieron algunas de sus obras impresas en París, en Lyon o en Ruán. Incluso fueron traducidos al francés antes de 1627 - es el caso de, al menos, Sabunde, Maldonado, Azpilcueta, Toledo, Tostado o Huarte.

Consecuentemente, la lengua en la que están publicadas la mayoría de las obras de autores españoles citadas por Naudé es el latín, la lengua franca del momento, pese a que en España muchos autores escribían en romance. De los citados, sólo Huarte — que fue traducido al francés en 1580- y Hurtado de Mendoza - que es citado en tanto que bibliófilo - escribieron corrientemente en español. Martín Azpilcueta, Tostado y Antonio Agustín emplearon el latín y el español en sus escritos. El resto escribieron principalmente en latín, lengua oficial en las universidades, que aún favorecía el intercambio intelectual más que las lenguas vernáculas.

Como ya se ha dicho, las excelsas plumas del siglo de oro español - Cervantes, Lope, Tirso de Molina, etc.- no son mencionadas por Naudé por exclusión metodológica y sistemática de los literatos; tampoco los ensayos de Francisco de Quevedo, quien compartía la admiración de Naudé por autores como Escalígero, Cardano, Boquelino o Persio. Más allá de las belicosas relaciones entre los reinos francés y español durante, al menos, la centuria que precedió a nuestro autor, se da otro tipo de antipatías -ideológicas, políticas o religiosas - más sutiles que no dejaría de influir en la elección pese al pretendido eclecticismo. El libertinismo y el galicanismo de Naudé inclinarían sus afectos del lado de monárquicos moderados partidarios de Enrique IV y 
del edicto de Nantes que, como Passerat o Pithou, habían proclamado en su día (1593) su oposición a los intereses de la monarquía española.

\section{LOS ESPAÑOLES CITADOS POR NAUDÉ}

En la relación de 26 españoles citados por Gabriel Naudé no hemos incluido a los antiguos ni a los altomedievales como Séneca, Marcial, Quintiliano, Higinio, Abenzoar, Agobardo e Isidoro de Sevilla — con los que la nómina ascendería a 33 personajes, un 9,17\% del total de citados en Recomendaciones - pese a haber nacido todos ellos en territorio hispano. Los 26 representan el 9,67\% del total de 269 autores modernos y bajo medievales (posteriores al año 1000) citados.

TABLA I. Españoles citados por Naudé

\begin{tabular}{|l|l|}
\hline $\begin{array}{c}\text { Personajes españoles citados (26) } \\
\text { ordenados cronológicamente }\end{array}$ & \multicolumn{1}{|c|}{ Razón de la cita de Naudé } \\
\hline Ramón Llull (1232-1315) & $\begin{array}{l}\text { [Citado dos veces: 1. entre otros] «curiosos } \\
\text { y no corrientes»... «a pesar de que la mayo- } \\
\text { ría no enseñan más que cosas vanas e inúti- } \\
\text { les y de que yo los considero unos escollos } \\
\text { para quienes se entretienen con ellos» (126). } \\
\text { 2. «En filosofía habría que comenzar por la } \\
\text { de Trimegisto... proseguir con la de Platón, } \\
\text { Aristóteles, Ramón Llull, Ramus...» (186) }\end{array}$ \\
\hline Velasco de Taranta (13??-1426) & $\begin{array}{l}\text { [Contradictoriamente citado dos veces] } 1 . \text { «es } \\
\text { cosa extraña y poco razonable que... tenga- } \\
\text { mos en tan alta estima a... Velasco... y a casi } \\
\text { todos los médicos modernos» (154) y 2. «que } \\
\text { sintamos vergüenza de dotar una biblioteca } \\
\text { con los libros de... Velasco» (154) }\end{array}$ \\
\hline Raimundo de Sabunde (1390-1436) & $\begin{array}{l}{[\text { Citado entre otros] «autores no porque }} \\
\text { sean mejores o más discretas y elocuen- } \\
\text { tes... sino porque se encuentran encuader- } \\
\text { nadas y contenidas en determinados volú- } \\
\text { menes» (148) }\end{array}$ \\
\hline Alonso Tostado (1400-1455) & $\begin{array}{l}{[\text { Citado dos veces junto a Salmerón: 1. }} \\
\text { como] «primero y principal autor.. para la } \\
\text { [teología] positiva» (111) y 2. «porque } \\
\text { tiene catorce volúmenes» (145) }\end{array}$ \\
\hline
\end{tabular}




\begin{tabular}{|c|c|}
\hline $\begin{array}{l}\text { Personajes españoles citados (26) } \\
\text { ordenados cronológicamente }\end{array}$ & Razón de la cita de Naudé \\
\hline Alfonso V de Aragón (1416-1458) & $\begin{array}{l}\text { [Citado dos veces, 1. entre quienes] «eran } \\
\text { aficionados y se afanaron particularmente } \\
\text { en reunir gran número de libros y ordena- } \\
\text { ron fundar bibliotecas muy interesantes y } \\
\text { bien dotadas» (89) y } 2 \text {. por una anécdota } \\
\text { que solía contar (101) }\end{array}$ \\
\hline Jiménez de Cisneros (1436-1517) & $\begin{array}{l}\text { [Su biblioteca] «bella y admirable, no es } \\
\text { tan concurrida ni está abierta a cualquiera, } \\
\text { ni es de tan fácil entrada» }(202)\end{array}$ \\
\hline Juan Martínez Guijarro (1486-1557) & $\begin{array}{l}\text { [Citado por ser] «primero y principal au- } \\
\text { tor... para la aritmética» }(113)\end{array}$ \\
\hline $\begin{array}{l}\text { Martín de Azpilcueta (1492-1586), «doc- } \\
\text { tor Navarro» }\end{array}$ & $\begin{array}{l}\text { [Citado junto a Toledo entre] «quienes mejor } \\
\text { han tratado partes de cualquier ciencia o } \\
\text { facultad, como... Navarro los casos de con- } \\
\text { ciencia» (116) }\end{array}$ \\
\hline Gómez Pereira (1500-1558) & $\begin{array}{l}\text { «En filosofía habría que... (incluir entre) } \\
\text { los innovadores a Gómez y... que son los } \\
\text { principales entre un millar de otros» (186) }\end{array}$ \\
\hline Diego Hurtado de Mendoza (1503-1575) & $\begin{array}{l}\text { [Citado dos veces: 1. La biblioteca] «de El } \\
\text { Escorial [creció] por otra grande que había } \\
\text { reunido Hurtado de Mendoza» (168) [y } 2 . \\
\text { porque] «mandó traer de Levante un navío } \\
\text { cargado de libros» (174) }\end{array}$ \\
\hline Juan Bautista Cardona (1511-1589) & $\begin{array}{l}\text { [Citado dos veces: 1. porque aconsejó] «para } \\
\text { formar y mantener la Real Biblioteca del } \\
\text { Escorial...» (80) [y 2. por los] «preceptos que } \\
\text { se pueden sacar de ciertos libros en los que } \\
\text { algunos autores han tratado ligeramente esta } \\
\text { materia [adquisición de libros]» (94) }\end{array}$ \\
\hline Alfonso Salmerón (1515-1585) & $\begin{array}{l}\text { [Citado dos veces junto a Tostado: } 1 \text { como] } \\
\text { «primero y principal autor.. para la [teolo- } \\
\text { gía] positiva» (111) y } 2 \text { 2. "porque tiene } \\
\text { ocho volúmenes» (145) }\end{array}$ \\
\hline Antonio Agustín (1515-1586) & $\begin{array}{l}\text { «Sería también un olvido manifiesto y una } \\
\text { falta inexcusable para quienes hacen profe- } \\
\text { sión de poseer los mejores libros el descuidar } \\
\text { alguno de, por ejemplo... Antonio Agustín... } \\
\text { y otros, cuyas obras hay que tomar a ojos } \\
\text { cerrados y sin dudarlo» (135-6) }\end{array}$ \\
\hline
\end{tabular}




\begin{tabular}{|c|c|}
\hline $\begin{array}{l}\text { Personajes españoles citados (26) } \\
\text { ordenados cronológicamente }\end{array}$ & Razón de la cita de Naudé \\
\hline Juan Bautista Montllor (152?-157?) & $\begin{array}{l}\text { «[Quienes] mejor comentaron o explicaron } \\
\text { determinado autor o libro en particular, } \\
\text { como ... Monllor ... los Analíticos» (116-7) }\end{array}$ \\
\hline Pedro Chacón (1527-1581) & $\begin{array}{l}\text { «Sería también un olvido manifiesto y una } \\
\text { falta inexcusable para quienes hacen profe- } \\
\text { sión de poseer los mejores libros el descui- } \\
\text { dar alguno de, por ejemplo, ... Chacón... y } \\
\text { otros, cuyas obras hay que tomar a ojos } \\
\text { cerrados y sin dudarlo» (135-6) }\end{array}$ \\
\hline $\begin{array}{l}\text { Juan Huarte de San Juan (1529-1588), } \\
\text { médico }\end{array}$ & $\begin{array}{l}\text { «Deberíamos valorar los libros pequeños } \\
\text { que tratan de cosas serias o de algún punto } \\
\text { relevante, pues el autor de estos últimos } \\
\text { domina enteramente su tema... Por ejem- } \\
\text { plo... el Examen de Ingenios de Huarte» } \\
(146-7)\end{array}$ \\
\hline Pedro Juan Núñez (1529-1602) & $\begin{array}{l}\text { «[Su biblioteca }] \text { no es tan concurrida ni } \\
\text { está abierta a cualquiera, ni es de tan fácil } \\
\text { entrada» }(202)\end{array}$ \\
\hline Pedro Juan Perpiñán (1530-1566) & $\begin{array}{l}\text { [Cita sus Oraciones] «no porque sean } \\
\text { mejores o más discretas y elocuentes... sino } \\
\text { porque se encuentran encuadernadas y } \\
\text { contenidas en determinados volúmenes» } \\
(148-9)\end{array}$ \\
\hline Francisco Toledo (1532-1596) & $\begin{array}{l}\text { [Citado junto a Navarro entre] «quienes } \\
\text { mejor han tratado partes de cualquier cien- } \\
\text { cia o facultad, como... Toledo... los casos } \\
\text { de conciencia» (116) }\end{array}$ \\
\hline Juan Maldonado (1534-1583) & $\begin{array}{l}\text { [Citado dos veces: } 1 \text {. entre quienes] «mejor } \\
\text { comentaron o explicaron determinado } \\
\text { autor o libro en particular, como... Maldo- } \\
\text { nado los Evangelios» (116-7) y 2. [entre } \\
\text { quienes] «no mandan a imprimir sus } \\
\text { obras» [por malograrse, carestía, censuras, } \\
\text { inseguridad o modestia y] «cuyos manus- } \\
\text { critos se encuentran...» (174-5) }\end{array}$ \\
\hline $\begin{array}{l}\text { Benito Pereira (1535-1610), profesor de } \\
\text { teología y filosofía, físico }\end{array}$ & $\begin{array}{l}\text { «QQuienes] mejor comentaron o explicaron } \\
\text { determinado autor o libro en particular, } \\
\text { como... Pereira el Génesis» }(116)\end{array}$ \\
\hline
\end{tabular}




\begin{tabular}{|l|l|}
\hline \multicolumn{1}{|c|}{$\begin{array}{c}\text { Personajes españoles citados (26) } \\
\text { ordenados cronológicamente }\end{array}$} & \multicolumn{1}{c|}{ Razón de la cita de Naudé } \\
\hline $\begin{array}{l}\text { Francisco Suárez (1548-1617), teólogo y } \\
\text { filósofo }\end{array}$ & $\begin{array}{l}\text { [Citado dos veces: 1. junto a Vázquez } \\
\text { como] «primero y principal autor.. para la } \\
\text { Escolástica» (112) y 2. porque «en verdad } \\
\text { que es cosa extraña y poco razonable que } \\
\text { sigamos y aclamemos, por ejemplo, a... } \\
\text { Suárez en materia de filosofía» (153) }\end{array}$ \\
\hline Gabriel Vázquez (1549-1604) & $\begin{array}{l}\text { [Citado junto a Suárez como] «primero y } \\
\text { principal autor.. para la Escolástica» (112) }\end{array}$ \\
\hline Tomás Sánchez (1550-1610) & $\begin{array}{l}\text { [Citado entre] «aquellos que escribieron y } \\
\text { publicaron libros y tratados sobre algún } \\
\text { tema particular concerniente a la especie o } \\
\text { al individuo, como Sánchez que trató am- } \\
\text { pliamente de matrimonio» (117) }\end{array}$ \\
\hline Francisco Sánchez (1551-1623) & $\begin{array}{l}\text { «No se debe descuidar a... Sánchez... que } \\
\text { intentaron trastocar todas las ciencias» (119) }\end{array}$ \\
\hline Juan Bautista Villalpando (1552-1608) & $\begin{array}{l}\text { [Citado entre] «aquellos que mejor comen- } \\
\text { taron o explicaron determinado autor o } \\
\text { libro en particular, como ... Villalpando a } \\
\text { Ezequiel» (116) }\end{array}$ \\
\hline
\end{tabular}

Citas referidas a las páginas de la edición española de 2008 .

Como se puede apreciar en la columna derecha de la Tabla I, no todas las citas responden a valoraciones positivas. Por tratarse de un manual para formar bibliotecas, algunas referencias son ejemplificaciones vía negativa de autores cuyo mayor mérito (siempre en opinión de Naudé) fue haber escrito demasiado o haber conseguido que sus obras fueran encuadernadas lujosamente (casos de Sabunde o Perpiñán, e, incluso, aunque reconociéndoles otros méritos, de Tostado y de Salmerón). El poeta y filósofo mallorquín Ramón Llull es citado en el dudoso apartado de «curiosos y no corrientes», en el que «la mayoría de ellos no enseñan más que cosas vanas e inútiles».

Sin pretender entrar en juicios de valor, pueden extrañar algunas ausencias, como la del erasmista Juan Luis Vives - al que Naudé citará en más de una ocasión en Consideraciones políticas sobre los golpes de estado (1639)—. Se echa en falta la mención a la edición de la Biblia políglota de Arias Montano - Naudé cita a un «Montano», pero se trata del médico italiano Gian Battista del Monte, apodado Montano-. Los logros de la Escuela de Salamanca quedan apenas re- 
saltados con la mención del doctor Navarro, de Francisco Suárez y de Gabriel Vázquez. Sin embargo, no parece que Naudé conozca o aprecie las aportaciones de los arbitristas, el probabilismo, los grandes logros hispanos en derecho internacional, natural y de gentes o en economía e ignora la historia natural americana. Para Naudé el doctor Navarro (Martín de Azpilcueta) no pasa de ser un moralista, mientras que, en general, entre los autores españoles, sólo cabía esperar teólogos positivos contrarreformistas y jesuitas, con algunas raras salvedades procedentes de la medicina. Si nos permitimos apuntar esas ausencias no es por enmendarle la plana a Naudé vindicando una lista paralela, sino por reforzar algo que parece obvio, el hecho de que la difusión en Francia de las obras haya sido un factor determinante en la elección del bibliotecario. En suma, la lista presentada por Naudé debería entenderse como una propuesta real de biblioteca sometida a todas las contingencias imaginables acaecidas en las librerías parisinas, sin descartar las carencias inherentes a la propia juventud del bibliotecario.

\section{LA PROFESIÓN DE LOS AUTORES Y LA CLASIFICACIÓN DE SUS OBRAS}

Entre los veintiséis españoles modernos o bajomedievales citados por Naudé, cuatro lo son exclusivamente en tanto que bibliófilos y no deberían considerarse propiamente autores con obra recomendada. Descartaremos pues en lo que sigue al rey Alfonso de Aragón, al cardenal Cisneros, a Núñez y a Diego Hurtado de Mendoza, con lo que la relación de autores citados por Naudé queda reducida a veintidós.

Al intentar clasificar los autores citados según sus respectivas especialidades encontramos no pocas dificultades. La adscripción de cada uno de estos autores a una determinada rama del saber es casi siempre problemática, pues los citados eran, en su mayoría, polígrafos eruditos, por lo que los esquemas actuales no son de gran ayuda. Casi todos los autores fueron eclesiásticos — prácticamente todos salvo los médicos - y muchos de ellos se dedicaban a la enseñanza de la teología, de la filosofía, de la filología, de la historia o de las matemáticas, pero, casi siempre, sus obras abarcaban más de una de dichas especialidades.

En esa tesitura, para analizar las obras de los autores mencionados hemos optado por encuadrarlos en apartados o rúbricas cercanos a los empleados por Naudé en sus Recomendaciones. De hecho, Naudé nos da la clave pues percibía la profesionalización, en el sentido de ejercer un arte o disciplina, como preferible al oscuro diletantismo literario y, así, en el capítulo IV afirma: 
para todo tipo de tratados particulares en materia de derecho, teología, historia, medicina, o cualquiera otra, con la única cautela de que aquella que se acerque más a la profesión que de ella se sigue sea preferible a las demás ${ }^{20}$.

Naudé se aproxima al criterio esgrimido en La piazza universale di tutte le professioni del mondo (1585) de Tomaso Garzoni, obra adaptada al español por Suárez de Figueroa como Plaza universal de todas las ciencias y artes (1615), en la que un fraile italiano y un jurista español ven la dificultad de sistematizar los conocimientos encajando edificios conceptuales donde las terminologías se ramifican y entrecruzan ${ }^{21}$. Los límites entre teología y filosofía, como los de la filosofía y las distintas ciencias eran extremadamente imprecisos en 1627 pues la actividad científica no estaba entonces institucionalizada, con la única excepción de la profesión médica, cuya enseñanza estaba reglamentada ${ }^{22}$. Por otra parte, en el XVII se asiste a una lenta mutación de los campos gnoseológicos desde las facultades medievales hacia las ciencias modernas. En consecuencia, en la Tabla II, al criterio expositivo de Naudé, no siempre coherente y en ocasiones redundante, hemos procurado superponer para las obras científicas, las clasificaciones más empleadas por los historiadores de la ciencia españoles ${ }^{23}$.

Se ha señalado además en la columna izquierda de la Tabla II la condición eclesiástica y la filiación de los autores citados, pues, como se ha dicho, salvo en el caso de los médicos, clerecía y erudición iban de la mano. Destaca la apabullante proporción de jesuitas: Salmerón, Perpiñán, Toledo, Maldonado, Benito Pereira, Francisco Suárez, Gabriel Vázquez, Tomás Sánchez y Villapando - al menos nueve entre los citados.

20 Naudé (2008), p. 118.

21 JaLÓN, M. (2006), Sobre las profesiones científico-técnicas en la Plaza universal de Suárez de Figueroa. Asclepio, 58 (1), 197-218. Véase además SuÁREZ DE FigueroA, C. (2006), Plaza universal de todas ciencias y artes (edición de JALÓN, M.), Valladolid, Junta de Castilla y León.

22 LÓPEZ PIÑERO, J.M. (1979), p. 47-50.

23 López Piñero, J.M. (1979), PARdo Tomás, J. (1991) o Arrizabalaga, J. (2002), El libro científico en la primera imprenta castellana (1485-1520), en GARCÍA BALLESTER, L. (dir.), Historia de la ciencia y de la técnica en la Corona de Castilla, Valladolid, Junta de Castilla y León, vol. II, pp. 619-649. 
TABLA II. Autores españoles y obras citadas o supuestamente citadas

\begin{tabular}{|c|c|}
\hline $\begin{array}{l}\text { Autores españoles citados (22) } \\
\text { clasificados por áreas temáticas }\end{array}$ & $\begin{array}{l}\text { Obra y/o edición explícita o } \\
\text { implícitamente citada }\end{array}$ \\
\hline \multicolumn{2}{|l|}{ Bibliografía, Historia, Filología } \\
\hline Juan Bautista Cardona (1511-1589), obispo & $\begin{array}{l}\text { De regia } S . \text { Laurentii bibliotheca de pontifi- } \\
\text { cia Vaticana de expungendis haereticor pro- } \\
\text { piis nominib. de diptychis (Tarragona, 1587) }\end{array}$ \\
\hline Antonio Agustín (1515-1586), arzobispo & [Todas sus obras], Opera omnia (Lyon, 1591) \\
\hline \multicolumn{2}{|l|}{ Filosofía } \\
\hline Ramón Llull (1232-1315), ¿fraile Menor? & $\begin{array}{l}\text { Ars Magna (numerosas ediciones, entre } \\
\text { ellas: Lyon, 1517) }\end{array}$ \\
\hline $\begin{array}{l}\text { Raimundo de Sabunde (1390-1436), mé- } \\
\text { dico y sacerdote }\end{array}$ & $\begin{array}{l}\text { Theologia naturalis, sive Liber creatura- } \\
\text { rum, ac specialiter de homine et de natura } \\
\text { ejus in quantum homo... (numerosas edi- } \\
\text { ciones, entre ellas: Lyon, } 1487-92 \text { y 1540) }\end{array}$ \\
\hline Francisco Suárez (1548-1617), jesuita & $\begin{array}{l}\text { [Tal vez] Disputationes metaphysicae (Sa- } \\
\text { lamanca, 1597; reed. París } 1605 \text { y 1619) }\end{array}$ \\
\hline Gabriel Vázquez (1549-1604), jesuita & $\begin{array}{l}\text { [No señala obra, constan publicaciones } \\
\text { anteriores a } 1627 \text { en Ingolstad, Amberes y } \\
\text { Maguncia] }\end{array}$ \\
\hline $\begin{array}{l}\text { Juan Bautista Montllor (152?-157?), sa- } \\
\text { cerdote }\end{array}$ & $\begin{array}{l}\text { [Podría tratarse de] Paraphrasis et scholio- } \\
\text { rum in duos libros priores analyticorum } \\
\text { Aristotelis (Valencia, 1569) [o de] Oratio } \\
\text { de utilitate Analyseos seu rationationis } \\
\text { Aristotelae (Francfort, 1591) }\end{array}$ \\
\hline Pedro Juan Perpiñán (1530-1566), jesuita & $\begin{array}{l}\text { [Presumiblemente] De humana, divinaque philo- } \\
\text { sophia discenda ad Parisienses Oratio (París, } \\
\text { 1566); Orationes quinque (Roma, 1565) }\end{array}$ \\
\hline \multicolumn{2}{|l|}{ Teología positiva } \\
\hline Alonso Tostado (1400-1455), obispo & $\begin{array}{l}\text { [Tal vez] Opera omnia quotquot in Scripturae } \\
\text { sacrae expositionem et alia (Venecia, 1596) }\end{array}$ \\
\hline Alfonso Salmerón (1515-1585), jesuita & $\begin{array}{l}\text { Commentarii in Evangelicam historiam et } \\
\text { in Acta apostolorum (Colonia, 1602, 1612) }\end{array}$ \\
\hline \multicolumn{2}{|l|}{ Teología moral } \\
\hline $\begin{array}{l}\text { Francisco Toledo (1532-1596), cardenal } \\
\text { jesuita }\end{array}$ & $\begin{array}{l}\text { Summa casuum conscientiae, sive Intro- } \\
\text { ductio Sacerdotum (Lyon, 1599; trad. al } \\
\text { esp. y al fr. en } 1602 \text { y muy reeditada) }\end{array}$ \\
\hline
\end{tabular}




\begin{tabular}{|c|c|}
\hline $\begin{array}{l}\text { Autores españoles citados (22) } \\
\text { clasificados por áreas temáticas }\end{array}$ & $\begin{array}{l}\text { Obra y/o edición explícita o } \\
\text { implícitamente citada }\end{array}$ \\
\hline $\begin{array}{l}\text { Martín de Azpilcueta (1492-1586), «doc- } \\
\text { tor Navarro», dominico }\end{array}$ & $\begin{array}{l}\text { Manual de confesores y penitentes (Coimbra, } \\
\text { 1553), [traducida al latín:] Enchiridion sive } \\
\text { Manuale confessariorum et paenitentium } \\
\text { (Amberes, 1575; más de cincuenta reed.) }\end{array}$ \\
\hline Tomás Sánchez (1550-1610), jesuita & $\begin{array}{l}\text { De Sancto Matrimonii Sacramento (Ma- } \\
\text { drid, 1602; reed. Lyon, 1621,1623, 1626) }\end{array}$ \\
\hline \multicolumn{2}{|l|}{ Comentarios bíblicos } \\
\hline Juan Maldonado (1534-1583), jesuita & $\begin{array}{l}\text { Commentarii in quatuor evangelistas } \\
\text { (Pont-à-Mousson, 1596); [trad. al fr.] } \\
\text { Traicté des anges et demons (París, 1605) }\end{array}$ \\
\hline Benito Pereira (1535-1610), jesuita & $\begin{array}{l}\text { Commentaria et Dissertationes in Genesim } \\
\text { (Roma, 1589-98) }\end{array}$ \\
\hline $\begin{array}{l}\text { Juan Bautista Villalpando (1552-1608), } \\
\text { jesuita }\end{array}$ & $\begin{array}{l}\text { Ezequielem explanationes et apparatus urbis } \\
\text { ac templi hierosolymitani commentariis et } \\
\text { imagibus illustratus (Roma, 1596-1604) }\end{array}$ \\
\hline \multicolumn{2}{|l|}{ Medicina } \\
\hline Velasco de Taranta (13?? -1426), médico & $\begin{array}{l}\text { Tractatus de epidemia et peste (Barcelona, } \\
\text { 1475); Practica usualis quae alias Philo- } \\
\text { nium dicitur (Lyon, 1490) }\end{array}$ \\
\hline Gómez Pereira (1500-1558), médico & $\begin{array}{l}\text { Antoniana Margarita (Medina del Campo, } \\
\text { 1554) }\end{array}$ \\
\hline $\begin{array}{l}\text { Juan Huarte de San Juan (1529-1588), } \\
\text { médico }\end{array}$ & $\begin{array}{l}\text { Examen de ingenios para las ciencias } \\
\text { (Baeza, 1575; trad. fr.: Lyon, 1589; París, } \\
1588,1605)\end{array}$ \\
\hline Francisco Sánchez (1551-1623), médico & $\begin{array}{l}\text { [Tal vez] De multum nobili et prima universa- } \\
\text { li scientia [o] Quod nihil scitur (Lyon, 1581) }\end{array}$ \\
\hline \multicolumn{2}{|l|}{ Matemáticas } \\
\hline $\begin{array}{l}\text { Juan Martínez Guijarro (1486-1557), } \\
\text { cardenal y matemático }\end{array}$ & $\begin{array}{l}\text { Ars arithmetica (París, 1513, 1514,1518, } \\
1526 \text { ) }\end{array}$ \\
\hline \multicolumn{2}{|l|}{ Astrología/Calendarios (Cronología) } \\
\hline Pedro Chacón (1527-1581), canónigo & $\begin{array}{l}\text { [Todas sus obras] Notae in vetus Romano- } \\
\text { rum Kalendarium (Amberes, 1574), De } \\
\text { Ponderibus, De Mensuris, De Nummis } \\
\text { (Roma, 1588) }\end{array}$ \\
\hline
\end{tabular}

Se ha procurado señalar la existencia de ediciones francesas que habrían propiciado la cita de Naudé. 
Ahora bien, decir que sólo 6 de los 22 autores citados eran científicos sería una imperdonable inexactitud. Aunque Naudé los cite como «comentaristas bíblicos», Benito Pereira fue un excelente físico y Villalpando un especialista en matemáticas y arquitectura, por ejemplo. Pero incluso aunque sólo 6 de los 26 autores citados lo fueran en tanto que científicos (un 23\%), la proporción es considerable. Entre los alemanes, dada la abundancia de teólogos (y heresiarcas), la ratio de científicos es inferior. Pardo Tomás estima que la publicación científica no superó la barrera del $10 \%$ del total de la producción ni en España ni en Europa ${ }^{24}$; cierto es que en Recomendaciones ya habían sido descartadas las obras literarias.

Algunas elecciones son bastante tópicas o «de oídas»; es curioso que Naudé recomiende los comentarios a los Evangelios de Maldonado y no los de Salmerón, de quien critica que sus comentarios sean excesivamente voluminosos. Años después, Pierre Bayle seguirá (como tantas veces, siempre inconfesas) la recomendación de Naudé e incluirá a Maldonado, pero no a Salmerón en el Dictionnaire historique et critique. Es extraño que de Benito Pereira cite los Comentarios del Génesis (obra también mencionada por Galileo), pero que ignore Adversus fallaces \& superstitiosas artes, id est de Magia, de observatione somniorum \& de divinatione astrologica, que había sido reeditado en Lyon en 1592.

No se libra pues la «selección española» de Naudé de la saludable «esgrima» entre los autores tan del agrado del parisino, que - aunque tendía a asociar, tal vez más de la cuenta, a los hispanos con Trento y con la Compañía de Jesús, constatando una cierta visión de España que se haría tópica- no dejó de manifestar su simpatía hacia quienes, rebelándose contra la fascinación de Aristóteles, innovaron la filosofía y trastocaron la ciencia, como Gómez Pereira, Francisco Sánchez o Huarte y, con similar entusiasmo, estimaba a ojos cerrados las obras de Antonio Agustín y de Pedro Chacón.

Aunque reconoce la autoridad en lo suyo de Tostado y Salmerón, o de Suárez y Vázquez — las dos antorchas de la Iglesia según Benedicto XIVtransmite Naudé la impresión crítica de que escribieron mamotretos. Pero la antipatía hacia Suárez - sobre quien desliza además una acusación de plagio $^{25}$ - puede tener otras explicaciones. El Parlamento de París - que presidía De Mesme, el patrón de Naudé- había ordenado en 1613 la quema de De Legibus, obra de Suárez en la que se justificaba la resistencia a los tiranos.

24 PARdo Tomás, J. (2002), La difusión de la información científica y técnica. En GARCÍA BALLESTER, L. (dir.), vol. III, p. 191.

25 NAUDÉ (2008), pp. 153-154. 
Los galicanos como Naudé juzgaban a los jesuitas responsables del asesinato de Enrique IV y proponían su expulsión de Francia. La doble mención a Suárez en Recomendaciones habla pues tanto del rigor del bibliotecario como del activismo del politólogo absolutista y maquiavélico que conviven en Gabriel Naudé.

\section{LA DIFUSIÓN INTERNACIONAL DE LOS AUTORES HISPANOS}

En el reconocimiento internacional de los autores hispanos influyó, es evidente, el hecho de que estos hubieran salido del país, algo que fue común a casi todos ellos. Así, Perpiñán, Maldonado y Martínez Guijarro fueron profesores en París; los médicos Velasco de Taranta y Francisco Sánchez ejercieron en Montpellier y Toulouse; Azpilcueta también fue profesor en Toulouse durante un tiempo. Tostado, Vázquez, Benito Pereira, Villalpando y Pedro Chacón, entre otros, enseñaron y vivieron en Roma, donde el Vaticano y el Colegio Romano atraían a los hombres de letras como potentes imanes.

Como puede apreciarse en la Tabla II, los autores citados — con las solas excepciones de Cardona y de Gómez Pereira, ambos con publicaciones en latín- habían publicado al menos una de sus obras fuera de España antes de 1627, la mayoría en Francia, principalmente en talleres de Lyon y París. La mayor parte de ellos publicó en latín, algunos en castellano, en algún caso vieron su obra traducida al francés (Huarte, Sabunde, Tomás Sánchez, etc.) con lo que la consiguiente difusión aumentó.

Las estancias de españoles en el extranjero - aparte de la eventual publicación y circulación de las obras en aquellos países - suponían en muchos casos el establecimiento de redes de relaciones intelectuales fecundas, como en el caso de Pedro Chacón, que en su estancia romana entabló amistad con Fulvio Orsini, Pinelli, Mercuriale, Alejandro Farnesio, Sirleto y otros grandes sabios de la época con los que después mantuvo correspondencia. Parecido fue el caso de Antonio Agustín y el de otros autores, de modo que la apertura al mundo con la consiguiente difusión y reconocimiento de las obras podría explicar caso por caso las menciones y las omisiones de Naudé. La progresiva impermeabilización de las fronteras españolas posterior a la pragmática de 1589 supuso una cortapisa al proceso de establecimiento de redes intelectuales y eruditas con el otro lado de los Pirineos que tan importante papel jugaron en la Revolución científica europea del XVII.

Sin duda, en la selección de Naudé influyeron factores externos: tanto de carácter editorial —es obvio que Naudé sólo podía recomendar lo que cono- 
cía personalmente, esto es, aquellos libros que circulaban en su tiempo por París-, como los aspectos políticos —en la elección no dejarían de pesar las vicisitudes políticas hispano-francesas, ya las internas de cada país como las externas derivadas de la mutua beligerancia a comienzos del siglo XVIIAhora bien, una vez ponderadas esas circunstancias, la elección da una idea bastante cabal de la considerable influencia e interés que la cultura española despertaba entonces.

La producción científica española se vio afectada por el aislamiento que siguió a las medidas represoras adoptadas hacia 1558, si bien se mantuvo por una cierta inercia hasta las primeras décadas del XVII. Desde Trento (15451563), los autores españoles fueron considerados en Europa como los campeones de la escolástica, en la que alcanzaron cotas inigualadas de rigor, aunque no situaron al país en las mejores condiciones para la Revolución científica en ciernes. La Contrarreforma exigía y la Inquisición aseguraba un sentido muy diferente a la aportación intelectual de las universidades españolas, volcadas todavía entonces en la teología moral y positiva y en la escolástica. Los estudios de tipo social, antropológico o etnológico se beneficiarían en cierta manera de este impulso debido a su mayor proximidad con aquellas temáticas y a la necesidad de desarrollo de los mismos planteado por la expansión del imperio colonial ${ }^{26}$. Sin embargo, los estudios experimentales y mecanicistas, aunque en principio menos enfrentados a los intereses contrarreformistas, fueron igualmente privados del flujo de libros e ideas y se vieron abocados a un desierto de cuya esterilidad sólo escaparon las obras puntuales $\mathrm{y}$ discontinuas de algunos médicos aislados ${ }^{27}$. Esto no debiera extrañar, pues mientras que las obras de arte e incluso el desarrollo de las humanidades gravitan frecuentemente en torno al genio de individualidades particulares, los hallazgos científicos son netamente productos de la sociedad de su tiempo referidos a una única realidad natural, por lo que dependen enormemente del flujo de la información y del conocimiento. D. J. S. Price ilustró la idea anterior confrontando la irrepetibilidad de un Miguel Ángel o de Beethoven con la aparición de autores que, más temprano que tarde, hubieran cubierto inexo-

26 Navarro Brotóns, V. y EAmon, W. (2007), Spain and the Scientific Revolution: Historiographical Questions and Conjectures. En: NAVARRO BROTÓNS, V. Y EAMON, W. (eds.), Más allá de la Leyenda Negra: España y la Revolución Científica, Valencia, Instituto de Historia de la Ciencia y Documentación López Piñero, p. 36.

27 Hubo más excepciones, como las relacionadas con la ingeniería, navegación, cosmografía, cartografía, metalurgia o historia natural americana, pero estas no las conoció Naudé. Véase, por ejemplo, CAÑIZARES-Esguerra, J. (2005), Iberian Colonial Science, Isis, 96, pp. 64-70. 
rablemente el hueco dejado por Copérnico y Galileo si estos no hubieran publicado sus obras ${ }^{28}$.

Las recomendaciones naudeanas no son eclécticas sino que están orientadas ideológicamente. Que Naudé fuera un erudito libertino, polemista, partidario de la monarquía absolutista francesa, admirador de Maquiavelo y galicano influyó sin duda en la elección de autores. La fama de contrarreformistas que caracterizaba a los españoles propició seguramente que Naudé etiquetara al sabio doctor Navarro de moralista o recomendara al físico Benito Pereira exclusivamente por su faceta de comentarista bíblico. En términos generales, el flujo de trabajos y autores españoles hacia Europa fue muy superior al de las obras extranjeras que circulaban por España, debido a las condiciones censoras soportadas en nuestro país durante la segunda mitad del siglo XVI y la primera del XVII. Las consecuencias fueron particularmente graves en el caso de las ciencias experimentales. Las citas de científicos españoles en la obra de Naudé confirman el argumento anterior. El estudio de los catálogos de las bibliotecas españolas de la época podría corroborarlo. Así pues, la visión tópica de una España escolástica que de alguna forma transmite Recomendaciones no será sólo achacable a las fobias políticas de Naudé.

La biblioteca ideal de Naudé ha de entenderse como una biblioteca universal y material. Universal porque Naudé tiene la intención dialéctica y polémica de incluir las obras de todos los mejores autores. Material en tanto que recomienda libros para una biblioteca física concreta ubicada en París en la tercera década del siglo XVII. Aquellos autores que viajaron, vivieron, se relacionaron y vieron sus obras impresas en Europa, preferiblemente en Francia, y, sobre todo, si sus obras fueron escritas en latín o traducidas al francés, tuvieron más fácil verse incluidos en la relación del bibliotecario. En contrapartida, una tal biblioteca, que había sido posible en el XVI, era impensable en la España del XVII que prohibía la importación de libros extranjeros.

Fecha de recepción: 1 de enero de 2008

Fecha de aceptación: 17 de noviembre de 2008

28 PRICE, D. J. de S. (1973), Hacia una ciencia de la ciencia, Barcelona, Ariel, 1973, p. 118. 
